\title{
Cournot Competition with Stranded Costs
}

\author{
José Antonio García Martín \\ Universitat Pompeu Fabra and CEMFI
}

Working Paper No. 0107

June 2001

I would like to express my sincere gratitude to my supervisor A. Jorge Padilla for his helpful suggestions and constant support. I have also benefited from the comments of Michael Manove, Rafael Repullo, Pedro Marín, and seminar audiences at the 25th Simposio de Análisis Económico in Barcelona, U. Pompeu Fabra, and CEMFI. All remaining errors are mine. (Email address: joseant@cemfi.es).

CEMFI, Casado del Alisal 5, 28014 Madrid, Spain.

www.cemfi.es 


\begin{abstract}
Recovery of stranded costs is perhaps the most litigious issue encountering regulators in promoting competition in United States and European utility industries. We build a dynamic model of Cournot competition which takes into account a particular regulatory mechanism regularly employed in United States and also in Spain for settling stranded costs payments, the competitive transition charges (CTC). Our results establish the conditions under which we are able to show that efficient competition and stranded costs recovery are not necessarily incompatible. Mechanism design is the key element in welfare analysis outcomes. Under ideal conditions we can prove that SCR payments can be used as a versatile regulatory tool to encourage competition and achieve allocative efficiency. On the contrary we also demonstrate that an unappropriated design of the SCR mechanism may deliver productive inefficiency in the market and delay or prevent desired new competition.
\end{abstract}

Keywords: Oligopolistic models, Regulation, Utilities. JEL Classification: D4, L5, L9, K2. 


\section{Introduction}

In recent years, regulated utility industries in many countries around the world, including the traditional natural monopolies such as electricity, natural gas and telecommunications in the United States, England and Wales, Norway, Sweden, Australia, Chile, Argentina, Venezuela and Spain, are facing a massive process of restructuring and liberalisation in order to establish the basis for a new competitive system. With the introduction of competition many infrastructure industries claim to have suffered the erosion of their asset values since competitive pressures are expected, in a perfectly competitive market, to encourage the prices to fall to "avoidable costs" and, so that, there is no more guarantee of a remunerative price (covering costs already sunk) for existing firms. The establishment of the new competitive framework could create a decline in income streams, thereby causing a lower valuation of a given asset in the market. On the basis of the existing regulatory setting, many assets were guaranteed a return that may not be recoverable following the introduction of a competitive market unless the transition is compensated. Infrastructure industries argue that deregulation interfered with reasonable investment-backed expectations and thus constitute a taking. So that, utilities claim that deregulation has produced stranded costs.

Joskow (2000) defines stranded or strandable costs for the utility-owned generating plants 'as the difference between the net book value of a generating plant used for setting cost-based regulated prices and the market value of that plant if it were required to sell it's output in a competitive market.' For contractual obligations, stranded costs are characterized by 'the difference between the present value of the contractual payment obligations and the net present value of the 
competitive market value of the electricity delivered under the contracts. ${ }^{1}$

Some other terms have also been used by analysts generally to describe stranded costs: strandable investments, stranded investments, stranded assets, stranded commitments, or transition costs. A wider concept of what is called strandable costs is also claimed by the utilities. The firms argue that the establishment of the new competitive framework interrupted the remuneration process under which companies undertook not only their investments on infrastructures but also their contractual obligations. Those costs, associated with these investments and incurred by the utility companies under the old regulatory system, which become uneconomic due to the introduction of a competitive market are known as stranded assets. Stranded liabilities are primarily long term contracts most of them mandated by the regulatory entity. ${ }^{2}$ Other elements included in the wider concept of stranded costs are regulatory assets and stranded social programs. The former are deferred expenses undertook by regulated utility industries whose reimbursement was promised by the regulatory entity to be in the future in order to limit the actual impact of these investments in actual regulated tariffs. The latter comprise a variety of social programs that the utilities have undertaken voluntarily or otherwise by virtue of being a regulated monopoly [Energy Information

\footnotetext{
${ }^{1}$ Rose-Ackerman and Rossi (2000) indicate that "stranded costs occur when the costs of incumbent exceed the costs to new entrants because of the actions of the state, not because of changes in technology or other exogenous economic shocks." Sidak and Spulber (1997) define stranded costs as the "inability of utility shareholders to secure the return of, and a competitive return on, their investment." Focusing more on capital outlays, Hovenkamp (1999) identifies stranded costs as "investments in specialized, durable assets that may seem necessary, or at least justifiable, when constructed and placed into service under a regime of prices and entry controls but that have become underutilized or useless under deregulation."

${ }^{2}$ For instance, the 1978 Public Utility Regulatory Act (PURPA) in the United States required utilities to purchase power produced by certain Qualyfing Facilities (QFs), primarily cogenerators and small power plants using renewable fuels. A similar regulatory measure prevails at present in Spain where Spanish government requires utilities to purchase national coal despite their low quality and high prices [Kahn (1998)].
} 
Administration (EIA) Report (1996)].3

Recovery of stranded costs is perhaps the major concern to many industry groups, especially to the electric utilities, and the most litigious issue encountering regulators in promoting competition. ${ }^{4}$ Utilities are looking for ways to mitigate stranded costs, and regulators are evaluating who should pay them. Most of the heated public debate, not only among economists but also between professors of law and political science, has been focused on two main directions.

First, the discussion about the legitimacy of the incumbent infrastructures compensation claims, whether regulators should give a regulated utility the opportunity to recover its stranded costs. ${ }^{5} \quad$ In principle, no government could or should indemnify investors against all of the hazards of business life. For instance, it can enact a general tax or can change policy so that an industry faces new regulatory costs or a contractual relation is affected, however, no compensation is required. In the general case the key policy issue is how to draw the line between the preservation of government flexibility as policymaking and the protection for infrastructure investors of "investment-backed expectations". Some, including Hunt and Shuttleworth (1996), have argued against the establishment

\footnotetext{
${ }^{3}$ Brennan and Boyd (1997), at 45, cited in Rose-Ackerman and Rosi (2000), supra note 77 at 28, also identify four types of stranded costs in the electric power sector: (1) Undepreciated investments in power plants that are more expensive than generators available today. (2) Long-term contracts most if not all mandated by PURPA. (3) Generators built but not used, primarily nuclear. (4) Expenses related to demand-side management (DSM) and other conservation programs that, as substitutes for new plant construction, were charged tot he generation side of the business.

${ }^{4}$ A detailed discussion covering the background of electric industry deregulation is contained in Energy Information Administration Report (1996).

${ }^{5}$ Alabama, Arizona, Arkansas, California, Connenticut, Delaware, Georgia, Idaho, Illinois, Iowa, Maine, Maryland, Massachusetts, Michigan, Mississippi, Montana, Nevada, New Hampshire, New Jersey, New York, Ohio, Oklahoma, Pennsylvania, Rhode Island, South Carolina, Texas and Virginia have established recovery mechanisms for payments of the stranded costs to electrical utility companies in the US.
} 
of stranded-cost recovery payments. ${ }^{6}$ Its arguments are essentially based on the believe that investors must face not just ordinary commercial risk, but also risk that flow from the actions of the state itself. By contrast, other opinions maintain that any action by government that negatively affects property rights should count as taking, so that no compensation should be claimed. Those arguing for stranded-cost compensations claim that even when there is no explicit contract the relationship between a utility and the state is based on an implied regulatory contract [Sidak and Spulber (1997)]. In its Order 888, the Federal Energy Regulatory Commission (FERC) reaffirmed its preliminary determination "that the recovery of legitimate, prudent and verifiable stranded costs should be allowed" in the belief that recovery of stranded costs is "critical to the successful transition of the electric industry to a competitive, open access environment."7 That is, FERC interpreted historical regulatory principles as a sort of "regulatory contract" [Joskow and Schmalensee (1986)]. On August 4, 1998, twelve European Community governments had already communicated to EC Energy Commission their purpose to compensate national power generation companies for their stranded costs. Only Italy, Finland and Sweden did not do it.

And second, once compensation of stranded costs are warranted, it has raised the debate around the appropriate methodology used to compute the accurate magnitude for the compensations to be recovered by the regulated utility indus-

\footnotetext{
${ }^{6}$ Hunt, S. and Shuttleworth, G., (1996) at pp.73: " The investors cannot have been blind to the coming of competition. Industry analysts have been writing about ir for years. The rates of return investors have been getting included the risk premium for increased competition and its consequences, and they should not bleat now that it has happened."

${ }^{7}$ Federal Energy Regulatory Commission, Order No. 888, Promoting Wholesale Competition Through Open Access Non-discriminatory Transmission Services by Public Utilities, Docket No. RM95-8-000, and Recovery of Stranded Costs by Public Utilities and Transmitting Utilities, Docket No. RM-94-7-001.
} 
tries. Estimates of projected stranded costs vary widely depending on the assumptions and methodology used. As a result it can be noted that initial estimates of stranded costs in electrical utility deregulation in the United States ranged from $\$ 10$ billion to $\$ 500$ billion. National Economics Research Associates (NERA), for example, estimates the stranded costs for the US electricity industry to be the difference between the short-run marginal costs of generation (in the range of 2 to 3 cents per kilowatt-hour) and the average costs (in the range of 5 cents per kilowatt-hour) for an unknown time period, so that its estimate of $\$ 500$ billion is at the upper bound of the spectrum. ${ }^{8} \quad$ Moody's Investor Service's estimate of total stranded costs for the investor-owned electric utilities is in the range of $\$ 50$ billion to $\$ 300$ billion, depending on market price assumptions. Defining breakeven price as the minimum price that a utility must charge to fully recover its fixed production costs, Moody's estimates the difference between a utility's break-even price and the market price for that capacity. Multiplying the difference by the total of a utility's capacity enables the derivation of stranded costs for any given year. These projections are extended for a 10-year period and then appropriately discounted to yield a net present value.

Separate from the debate over "How much should utilities be allowed to recover?" is the question, "How do you recover it?". The answer to this question has fundamental implications for the efficient development of a competitive market. While regulators may accede to the recovery of stranded costs to existing companies, not infrequently they underestimate the difficulty of designing an appropriate cost recovery mechanisms in a competitive system. ${ }^{9}$ Certainly, not

\footnotetext{
${ }^{8}$ See National Economic Research Associates, 'Rewriting the Rules of the Road: Retail Wheeling and Competition in Electric Generation' (New York, NY, March 1994).

${ }^{9}$ Kahn (1994), Supra note 5, at 35, asserts:

- it is at least as important from the efficiency standpoint that customers' decisions about
} 
much attention has been paid to the potential distortions that the recovery of stranded costs can create in these recently created competitive markets. Existing economic theory does poorly at explaining these latent distortions.

This paper focuses primarily on the welfare analysis of a dynamic competitive market in which regulatory mechanisms have been implemented to allow utility industry the recovery of stranded costs. Rather than addressing the justifications for the recovery of stranded costs or computing the precise magnitude for the compensations, this paper examines a single arena: welfare implications and price incentives created by the settlement of stranded-cost recovery mechanisms in a dynamic market.

A frequent claim made against measures purporting to ensure the recovery of stranded costs is that these provisions necessarily lead to inefficient competition, above marginal-cost pricing, inefficient despatching, erection of barriers to entry, etc. (See Kühn and Regibeau ,1998, and Lasheras, 1998). In a context of liberalization of entry Jullien and Kühn (1998) show how optimal regulation involving a menu of price caps and price floors could optimally finance stranded assets when government transfers to firms are not permitted. Kahn (1994) and Joskow (1996) also deal with the stranded-cost issue. While Kahn (1994) discusses the need for the coexistence of competition and regulation in the electric power industry, Joskow (1996) also provides simple mechanisms to implement stranded-cost recovery policies that promote efficient competition. In Chaper 3 of this dissertation, I have developed an auction model to analyze spot market competition with stranded costs in the deregulated Spanish electricity market in an static duopolis-

whether or not to desert their present requirements suppliers be influenced by the proper signals, reflecting the respective true social (i.e., marginal) costs of the alternatives, as that the utility companies be enabled to recover their regulatory determined revenue requirements. 
tic game and also confirm that 'the implementation of stranded-cost recovery in the market does not necessarily create additional distortions in the competition, at least no more than those that already appear in a typical spot market without stranded costs'. The purpose of the paper is to show that efficient competition and stranded-cost recovery are not necessarily incompatible in the context of an oligopoly dynamic market. Our results establish the conditions under which I should expect cost shifting practices to be avoided. These conditions enable me to show that, under optimal conditions, in a market with stranded costs only consumer surplus matters for welfare analysis. Even though the paper reveals that an optimal stranded-cost recovery policy can act as a countervailing force to market power and high prices, it also demonstrates that, contrary to the predictions of the typical Cournot model, higher prices can improve consumer surplus and thus total social welfare. More importantly, my model is the first to take explicitly into account the settlement of stranded-cost recovery mechanisms in a dynamic environment. The paper describes a particular regulatory mechanism regularly employed in United States and also in Spain for settling stranded-cost payments, the competitive transition charges (CTC). ${ }^{10}$

The paper is organized as follows. Section 2 presents my model and discusses the assumptions. Section 3 is devoted to analyze the model for the basic symmetric case. Section 4 extends the model to deal with asymmetric cases. Finally, section 5 concludes.

\footnotetext{
${ }^{10}$ For more details about the mechanism designed for settling stranded-cost payments in Spain, see Royal Decree 2019/1997, December 26, 1997, (Real Decreto por el que se organiza y regula el procedimiento de liquidación de los costes de transporte, distribución y comercialización a tarifa, de los costes permanentes del sistema y de los costes de diversificación y seguridad de abastecimiento).
} 


\section{The Model}

I consider a dynamic game of Cournot competition with stranded-cost recovery payments. Let $q_{i t}$ denote the quantity that firm $i$ supplies to the market at period $t, i=1, \ldots, n, t=1, \ldots, T$, and $q_{-i t}$ represent the quantity supplied by the whole industry but firm $i$ at period $t$,

$$
q_{-i t} \equiv q_{1 t}, \ldots, q_{i-1, t}, q_{i+1, t}, \ldots, q_{n t} .
$$

In the basic model, the costs functions of firms are symmetric producing every unit $q_{i t}$ at constant marginal cost, $c$. The demand for the product sold by the firms is represented by $p_{t}\left(q_{i t}, q_{-i t}\right)$ and for simplicity, it is assumed that $p_{t}\left(q_{i t}, q_{-i t}\right)=$ $A-\sum_{i=1}^{n} q_{i t}$, i.e., a standard linear demand. Each firm in the game obtains payoffs from two different routes: the production "market" and stranded-cost recovery payments. And thus, the price $p_{t}($.$) determines not only the payoffs that firms$ obtain via production, but also the revenues that firms obtain via stranded-cost recovery payoffs (SCR, hereafter).

Firm $i$ 's production payoffs at period $t, \Pi_{i t}\left(q_{i t}, q_{-i t}\right)$, are determined by the quantity supplied to the market by the industry at the current period $t$, so that, only contemporaneous quantities affect current production payoffs. For each firm $i$ production revenues at period $t$ are given by the equation below,

$$
\Pi_{i t}(.)=\left(p_{t}-c\right) q_{i t}, \quad i=1, \ldots, n ; t=1, \ldots, T .
$$

I assume that the horizon is finite: $T<+\infty$.

Firm $i$ 's SCR revenues are only paid at the end of the game, at period $T$. Unlike current production revenues which depend on contemporaneous prices, SCR revenues are contingent also on past and future prices through the whole period game, 
$\widehat{p}\left(q_{i 1}, q_{-i 1} ; \ldots ; q_{i T}, q_{-i T}\right)$. The reference price, $\widehat{p}$, is determined as a industryweighted average price in the following manner:

$$
\widehat{p}(.) \equiv \frac{\sum_{k=1}^{T} \sum_{j=1}^{n} \beta^{k-T} p_{k} q_{j k}}{\sum_{k=1}^{T} \sum_{j=1}^{n} q_{j k}} .
$$

Let $S(\widehat{p}()$.$) be a continuous and monotonically decreasing function which$ denotes the SCR payoffs to be paid for the whole industry when the (quantityweighted) average price is $\widehat{p}($.$) , and \bar{S}$ be the maximum amount of SCR payoffs to be paid to the whole industry, i.e., $0 \leq S(\widehat{p}().) \leq \bar{S}$. Furthermore, I assume that $S(c)<\bar{S}, S(\bar{p})>0$ and $S(\widehat{p}().) \equiv \bar{S}, \forall \widehat{p} \leq p_{r}$. Consequently, given that $S(c)<\bar{S}$ and $S^{\prime}(\widehat{p}()) \leq$.0 , I have that $p_{r}$, the price that maximizes SCR payoffs, is strictly less than $c$, the common marginal cost of production.

I denote by $S^{*}$ the reference $S C R$ payment set by the regulator for the whole industry at the beginning of the game. The reference SCR payment has been determined ex ante as a function of the expected demand and the reference price $p^{*} \in[0, \bar{p}]$. Ex post, once the game has finished at period $T$ and the (quantityweighted) average price, $\widehat{p}($.$) , has been calculated by the regulator, the SCR$ payoffs corresponding to the industry are given by,

$$
S(\widehat{p}(.))=S^{*}-\left[\left(\widehat{p}(.)-p^{*}\right) \sum_{j=1}^{n} \sum_{k=1}^{T} q_{j k}\right] .
$$

Total SCR payoffs are thus a function of the difference between the (quantityweighted) average price, $\widehat{p}($.$) , and the reference price, p^{*}{ }^{11}$ Therefore, a reduction in the (quantity-weighted) average price, increases the revenues accruing from stranded-cost recovery. A (quantity-weighted) average price, $\widehat{p}($.$) , higher than p^{*}$

\footnotetext{
${ }^{11}$ In the spirit of the Law these reference price, $p^{*}$, is expected to reflect the forecasted competitive price in the recent liberalized market.
} 
will generate SCR payoffs for the industry lower than the reference SCR payoffs, $S^{*}$, and vice versa. So that,

$$
S(\widehat{p}(.)) \geq S^{*} \text { iff } \widehat{p}(.) \leq p^{*}
$$

Total SCR payoffs, $S(\widehat{p}()$.$) , are shared among generators as established by law.$ Let $\theta_{i}$ denote the firm $i$ 's SCR share, so that $\theta_{i} \in(0,1), i=1, \ldots, n$, and $\sum_{i=1}^{n} \theta_{i}=$ 1. This means that, ex post, at period $T$ when the average price, $\widehat{p}($.$) , has been$ announced, the SCR payoffs corresponding to firm $i$, are given by,

$$
S_{i}(\widehat{p}(.))=S(\widehat{p}(.)) \theta_{i}, \quad i=1, \ldots, n
$$

From equation (3) and equation (5), and replacing equation (2) into the previous one I have that

$$
S_{i}\left(\widehat{p}_{i}(.)\right)=\left[S^{*}-\left(\widehat{p}(.)-p^{*}\right) \sum_{j=1}^{n} \sum_{k=1}^{T} q_{j k}\right] \theta_{i}, i=1, \ldots, n .
$$

It can be noted that all the firms share the SCR payoffs equally when their SCR shares coincide, independently of their offer prices. Replacing equation (2) into equation (6) and rearranging the terms I can write the previous equation as:

$$
S_{i}(\widehat{p}(.))=\left[S^{*}-\sum_{j=1}^{n} \sum_{k=1}^{T}\left(\beta^{k-T} p_{k}-p^{*}\right) q_{j k}\right] \theta_{i}, i=1, \ldots, n .
$$

Unlike production payoffs which at date $t$ are only affected by current quantities, SCR payoffs depend on the history of previous and coming quantities, since they depend on the (quantity-weighted) average price, $\widehat{p}($.$) . Thus, the quantity$ strategy $q_{i t}$ depends on the history

$$
H_{t} \equiv\left(q_{i 1}, q_{-i 1} ; \ldots ; q_{i, t-1}, q_{-i, t-1}\right)
$$


At each date $t$, the firms choose their quantities, $\left(q_{i t}\left(H_{t}\right), q_{-i t}\left(H_{t}\right)\right)$, simultaneously, given the history $H_{t}$. Firm $i$ 's intertemporal profit in any period $t, \widetilde{\Pi}_{i t}\left(q_{i t}, q_{-i t}\right) \equiv \tilde{\Pi}_{i t}$, is then given by,

$$
\begin{aligned}
& \tilde{\Pi}_{i t}=\underbrace{\sum_{k=t}^{T} \beta^{k-t} \Pi_{i k}}+\underbrace{\beta^{T-t} S_{i}(\widehat{p}(.))}, i=1, \ldots, n ; t=1, \ldots, T, \\
& \text { Production SCR } \\
& \text { Revenues Revenues }
\end{aligned}
$$

where $\beta<1$ is the common discount factor of the firms. ${ }^{12}$ The first term in (8) reflects the present discounted value of firm $i$ 's expected production revenues. The second part of (8) represents the present discounted value of firm $i$ 's SCR payoffs, given all the actions chosen by every firm at dates 1 through $T$.

Replacing equation (1) and equation (6) into equation (8) and rearranging the terms I have that firm $i$ 's intertemporal is given by

$$
\begin{array}{r}
\tilde{\Pi}_{i t}=\left(p_{t}-c\right) q_{i t}+\beta^{T-t}\left[S^{*}-\left(\widehat{p}(.)-p^{*}\right) \sum_{j=1}^{n} \sum_{k=1}^{T} q_{j k}\right] \theta_{i}, \\
i=1, \ldots, n, t=1, . ., T .
\end{array}
$$

Let me consider the first-order condition for profit maximization for firm $i$ at period $t, \frac{\partial \tilde{\Pi}_{i t}}{\partial q_{i t}} \equiv \tilde{\Pi}_{i t}^{\prime}$ :

$$
\begin{array}{r}
\tilde{\Pi}_{i t}^{\prime}=p_{t}(.)-c+q_{i t} \frac{\partial p_{t}(.)}{\partial q_{i t}}-\beta^{T-t}\left[\left(\widehat{p}(.)-p^{*}\right)+\frac{\partial \widehat{p}(.)}{\partial q_{i t}} \sum_{j=1}^{n} \sum_{k=1}^{T} q_{j k}\right] \theta_{i}=0, \quad \\
i=1, \ldots, n, t=1, . ., T .
\end{array}
$$

\footnotetext{
${ }^{12} \beta$ could be denoted as $\beta=e^{-r \tau}$, where $r$ is the instantaneous rate of interest and $\tau$ is the real time between "periods". $\beta$ close to 1 represents low impatience, or rapid quantity changes. $\beta$ close to 1 represents low impatience, or rapid quantity changes.
} 
This has a simple interpretation. The first three terms yield the profitability of an extra unit of output in terms of production payoffs, which is equal to the difference between price and marginal cost (the first two terms) plus the effect of this extra unit on the profitability of the inframarginal ones (the third term). The extra unit creates a decrease in price, $\frac{\partial p_{t}(.)}{\partial q_{i t}}$, which affects the $q_{i t}$ units already produced. The fourth term yields the profitability of an extra unit of output in terms of SCR payments. The extra unit creates a variation in SCR payments for the whole industry which is equal to the difference between the weighted average price, $\widehat{p}($.$) , and the reference price, p^{*}{ }^{13}$ Furthermore, the extra unit creates a decrease in the industry-weighted average price, which again affects not only the $q_{i t}$ units already produced by firm $i$ at the current period $t$ but also the aggregate quantities produced by the whole industry for all the periods in the game, $\sum_{j=1}^{n} \sum_{k=1}^{T} q_{j k}$. The positive effect of this extra unit on firm $i$ 's SCR payments is proportional to its share on total stranded-cost payoffs, $\theta_{i}$.

The preceding analysis actually reflects the externalities between the firms. To the typical negative externality that I can find in a standard Cournot market without stranded costs, ${ }^{14}$ I must add now those ones that arise when I introduce SCR payoffs in the standard Cournot game: When choosing its output firm $i$ perceives the effect of the extra unit on SCR payments only partially, $\left(i . e, \theta_{i}\left(\widehat{p}()-.p^{*}\right)\right)$, rather than the total effect, $\left(\widehat{p}()-.p^{*}\right)$. This externality may be positive or negative depending on the sign of the difference between the weighted-average price

\footnotetext{
${ }^{13}$ The varaition in SCR payments can be positive or negative depending on the sign of the difference between $\widehat{p}_{i}($.$) and p^{*}$.

$14 \ldots$...W]hen choosing its output, firm $i$ takes into account the adverse effect of the marketprice change on its own output, rather than the effect on aggregate output. Hence, each fim will tend to choose an output that exceeds the optimal output from the industry's point of view. [Tirole, 1998, pp. 219]
} 
and the reference price. Moreover, a positive externality also arises between firms. When deciding its output firm $i$ takes into account the positive effect of the weighted-average-price change only in part, $\left(i . e, \theta_{i} \sum_{j=1}^{n} \sum_{k=1}^{T} q_{j k}\right)$, rather than the effect on total aggregate output. So that, the total effect of these three externalities on the behavior of the firms is ambiguous and I can not obtain direct conclusions without a more extensive analysis of the parameters of the model.

\section{The Analysis}

In this section, I find and characterize the Nash equilibria of the model presented above. For simplicity let me consider first the analysis of a duopoly market (i.e., $n=2$ ) as a benchmark case.

\subsection{The Basic Duopoly case}

Let me consider the first-order condition for profit maximization for a duopoly case at each date $t$. Each firm maximizes its profit given the quantity chosen by the other firm. From equation (10) and since I have assumed a linear demand, $p_{t}\left(q_{i t}, q_{j t}\right)=A-q_{i t}-q_{j t}, t=1,,, T$, I get

$$
\frac{\partial\left(\tilde{\Pi}_{i t}\right)}{\partial q_{i t}}=A-2 q_{i t}-q_{j t}-c+\left[\beta^{T-t} p^{*}+q_{j t}-\left(A-2 q_{i t}-q_{j t}\right)\right] \theta_{i}=0,
$$

$$
i \neq j, i, j=1,2, t=1, . ., T \text {. }
$$

It can be noted from the previous equation that $q_{i t}$ depends only on time $t$ variables, that is, firm $i$ 's marginal profits present additive separability properties. It implies that in order to choose its output each firm takes only into 
account rival's contemporaneous quantities and it is affected neither by rival's non-contemporaneous quantities nor its own non-contemporaneous quantities.

Since the profit function is strictly concave in $q_{i t}$ and twice differentiable, and because of the additive separability property of the marginal profit function I can get

$$
q_{i t}=R_{i t}\left(q_{j t}\right)
$$

where $R_{i t}$ is firm $i$ 's reaction curve at period $t$ :

$$
\frac{\partial\left(\tilde{\Pi}_{i t}\right)}{\partial q_{i t}}\left(R_{i t}\left(q_{j t}\right), q_{j t}\right)=0, t=1, \ldots, T .
$$

A Nash equilibrium in the model is a pair of actions $\left(q_{i t}^{e q}, q_{j t}^{e q}\right)$ such that $q_{i t}^{e q}=$ $R_{i t}\left(q_{j t}^{e q}\right)$ and $q_{j t}^{e q}=R_{j t}\left(q_{i t}^{e q}\right)$. In such an equilibrium each firm reacts optimally to other firm's anticipated action. Solving equation (11) in terms of $q_{i t}$ I obtain the reaction functions:

$$
\begin{gathered}
q_{i t}=R_{i t}\left(q_{j t}\right)=\frac{1}{2}\left\{(A-c)-\left[\left(1-\xi_{i}\right) q_{j t}-\xi_{i}\left(\beta^{T-t} p^{*}-c\right)\right]\right\}, t=1, . ., T, \\
\text { where } \xi_{i} \equiv\left(\frac{\theta_{i}}{\theta_{j}}\right) .
\end{gathered}
$$

The term $\xi_{i}$ is a measure of the degree of asymmetry in the distribution of the SCR payments among the firms in the market. Note that $\xi_{i}=1$ if and only if SCR payments are equally shared among both firms in the market, i.e., $\theta_{i}=$ $\theta_{j}=\frac{1}{2}$. Values of $\xi_{i}$ higher (lower) than 1 identifies those situations in which SCR payments are asymmetrically shared among both firms in the market and firm $i$ obtains a higher (lower) quota of SCR payments. Note that

$$
\xi_{i}, \xi_{j} \in(0, \infty) \text {, and } \xi_{i}>1 \text { iff } \xi_{j}<1
$$


The intuition behind equation (12) is as follows. A crucial element in the analysis of the model is the sign of the slope of the reaction functions for the strategic variables I am considering. Its sign is going to give me information about the response of each firm to rival's choices. This slope is obtain by differentiating equation (12):

$$
R_{i t}^{\prime}\left(q_{j t}\right)=\frac{1}{2}\left(\xi_{i}-1\right)
$$

Unlike in a typical Cournot game in which quantities, for both firms, are strategic substitutes, ${ }^{15}$ in a model with SCR payments the response of each firm to aggressive play by the rival can be divergent. The different allocation of SCR shares among firms, $\xi_{i}$, plays a crucial role in the determination of the firms' equilibrium strategies, since as it is clear from (12),quantity responses depend on the sign of $\xi_{i}$. For instance, if the SCR payments are equally shared among firms, i.e., $\xi_{i}=\xi_{j}=1$, then firms choose their quantities independently of the quantity its rival is supplying at the market. Note that in that case

$$
R_{i t}^{\prime}\left(q_{j t}\right)=R_{j t}^{\prime}\left(q_{i t}\right)=0
$$

so that neither firm $i$ nor firm $j$ respond to the anticipation of a more aggressive play by the rival. In such a case the equilibrium solution is given by

$$
q_{i t}^{e q}=q_{j t}^{e q}=\frac{1}{2}\left\{(A-c)+\left(\beta^{T-t} p^{*}-c\right)\right\}, t=1, \ldots, T .
$$

Let's analyze the case in which SCR payments are asymmetrically allocated. Without loss of generality I am assuming that $\theta_{i}>\theta_{j}$. It can be easily shown

\footnotetext{
${ }^{15}$ In an standard Cournot model we have that firms becomes less aggressive in the face of more aggressive play by the rival $\left[i . e ., R_{i t}^{\prime}\left(q_{j t}\right)<0\right.$ and $\left.R_{j t}^{\prime}\left(q_{i t}\right)\right]$, we then say that quantities are strategic substitutes.
} 
that now I have that $\xi_{i}>1$ whereas $\xi_{j}<1$, and thus, from equation (13) I get:

$$
\begin{gathered}
R_{i t}^{\prime}\left(q_{j t}\right)=\frac{1}{2}\left(\xi_{i}-1\right)>0, \text { and } \\
R_{j t}^{\prime}\left(q_{i t}\right)=\frac{1}{2}\left(\xi_{j}-1\right)<0 .
\end{gathered}
$$

From the preceding results I can conclude that an increase in $q_{j t}$ by firm $j$ induces firm $i$ to higher its choice of $q_{i t}$, I say that, for firm $i, q_{j t}$ is a strategic complement of $q_{i t}$. Firm $i$ becomes more "aggressive" in response to a higher level of $q_{j t}$. Diametrically different is the reaction of firm $j$ to the increment of an extra unit of output by firm $i$. The extra unit of output by firm $i$ makes firm $j$ less "aggressive". A higher level of $q_{i t}$ by firm $j$ 's rival lowers firm $j$ 's profit. Hence, firm $j$ would be better off, all else being equal, if it could induce firm $i$ to lower its choice of $q_{i t}$, I have that $q_{i t}$ is a strategic substitute of $q_{j t}$. The intuition behind this behavior is the following. When firm $i$ 's SCR share is increased the best-response function for firm $i$ changes. An extra unit of output in the market generates the same alteration in production payoffs than before but now the effect on firm $i$ 's SCR payoff are stronger. As long as SCR payoffs are a decreasing function of the weighted-average price, firm $i$ would be better off, all else being equal, with a lower market price, and thus with a higher level of total quantity. Since an increase of firm $i$ 's SCR share implies a lower level of firm $j$ 's SCR share, now the importance of SCR payments on firm j's profit function diminishes. Hence, firm $j$ 's efforts are now more focused on the possibility of obtaining incomes through production payoffs. As in a typical Cournot model firm $j$ 's best-response function to a higher level of its rival's output is to become less aggressive and reduce its output, [i.e., $\left.R_{j t}^{\prime}\left(q_{i t}\right)=\frac{1}{2}\left(\xi_{j}-1\right)\right]$. However this reduction is lower than that one which would have occurred in an otherwise identical market without stranded 
costs payments, [i.e., $\left.R_{j t}^{\prime}\left(q_{i t}\right)=-\frac{1}{2}\right]$. The negative influence of the extra unit of output on its profits are lower because firm $j$ still obtains a certain proportion of SCR payments. [See Figure 1]

From the previous analysis it results that firm $i$ responds in kind to more aggressive choices of $q_{j t}$ by firm $j$. Furthermore I know that in spite of $q_{i t}$ being a strategic substitute of $q_{j t}$, the magnitude of firm $j$ 's best-response function to an increase in rival's quantity is lower than that one which would have occurred in an otherwise identical market without stranded costs payments. Thus, the aggregate quantity at equilibrium will be higher that the aggregate output in an otherwise identical pool market with stranded costs. That is, equilibrium prices in a market without stranded costs are higher than market prices in a market with stranded costs. Therefore, starting from a situation without stranded-cost repayments, these costs necessarily strengthen overall competition.

From equation (11) it can be easily proved that the Nash equilibrium of the game is given by:

$$
\begin{gathered}
q_{i t}^{e q}=\theta_{i}(A-c)+\left(3 \theta_{i}-1\right)\left(\beta^{T-t} p^{*}-c\right) t=1, \ldots, T, \\
q_{j t}^{e q}=\theta_{j}(A-c)+\left(3 \theta_{j}-1\right)\left(\beta^{T-t} p^{*}-c\right), t=1, \ldots, T .
\end{gathered}
$$

Let $Q_{t}^{e q} \equiv q_{i t}^{e q}+q_{j t}^{e q}$, hence I obtain that aggregate equilibrium quantity at each period $t$ is then given by

$$
Q_{t}^{e q}=A-c+\left(\beta^{T-t} p^{*}-c\right), t=1, \ldots, T
$$

which yields

$$
p_{t}^{e q}=A-Q_{t}^{e q}=c-\left(\beta^{T-t} p^{*}-c\right), t=1, \ldots, T .
$$


Equilibrium outputs in an otherwise identical market without SCR payments are given by the typical Cournot solution where

$$
Q_{t}^{C o}=\frac{A-c}{3}
$$

and

$$
p_{t}^{C o}=\frac{A+2 c}{3} .
$$

From this point on and for simplicity, let me consider the following relations:

$$
\lambda \equiv A-c \text { and } \gamma_{t} \equiv \beta^{T-t} p^{*}-c
$$

Thus, comparing both results I obtain the following result:

Proposition 1 At each period the Nash equilibrium of the duopoly model have the following properties:

a. The aggregate equilibrium quantity is not contingent on the distribution of SCR shares.

b. And hence, the equilibrium price in the market is independent on the allocation of SCR payments among firms.

c. The existence of SCR payments necessarily encourage overall competition in the market forcing unambiguously to lower prices.

d. The higher-SCR share firm supplies at the market larger quantities than the lower-SCR share firm. Thus, the firm's market share is proportional to its $S C R$ allocations.

e. If $\gamma_{t}>0$, I can find in equilibrium market prices below marginal cost.

f. Setting always the reference price at marginal cost is suboptimal. If $\gamma_{t}=0$, then marginal cost pricing is the equilibrium strategy for this Cournot game. 
Consequently, equilibrium outputs in the whole game are totally independent on the allocation of SCR payments among the players. Changes on the distribution of SCR payments alter the allocation of SCR payments among firms in a redistributive way while equilibrium outputs remain unaffected. An important conclusion is also to find that the presence of SCR payoffs induce fiercer competition and lead firms to larger quantities than in an otherwise identical market without stranded costs. Thus the market price will be lower than the equilibrium price in a standard Cournot game. The existence of SCR payments mitigates the interests of the firms in increasing prices. This is because the stranded costs component paid by all consumers is calculated in a way that moves inversely to the market price. Furthermore, it can be the case that I can find in equilibrium market prices below marginal cost. Note that this fact does not imply that firms present negative profits in equilibrium. Since firms in the market are paid SCR payments, an equilibrium price below marginal cost only indicates negative production payoffs but strictly positive SCR payments larger than individual SCR allocation, $\theta_{i} S^{*}$. Result $e$. indicates that the lower-SCR share generator submits lower quantities at the market than the higher-SCR share firm. This is an intuitive conclusion because it reveals that the more asymmetric the SCR shares, the less tempted the lower-SCR share firm is to exploit its SCR payments. I can also conclude that whenever the regulator is able to settle the reference price, $p^{*}$, as a time-adjustment of the marginal cost, (i.e., $\left.p_{t}^{*}=\frac{c}{\beta^{T-t}}\right)$, then I have that marginal cost is induced to be the equilibrium price for the whole game. Thus, setting the reference price at marginal cost is suboptimal. Solving equation (20) I get

$$
p_{t}^{e q}=c \Leftrightarrow p_{t}^{*}=\frac{c}{\beta^{T-t}}, t=1, \ldots, T .
$$

From the equation below it can be inferred that the optimal reference price (from 
the regulator's point of view) must be always larger than the marginal cost, but for the last period game, $T$. That is

$$
p_{t}^{*}=\frac{c}{\beta^{T-t}} \geq c, t=1, \ldots, T
$$

And thus, I have as an optimal reference price a dynamic reference price, $p_{t}^{*}$, which is proportional to the marginal cost and the length of the SCR period, $T$, and inversely proportional to the discount rate.

In general, we have demonstrated that there exists a mechanism which implements the First Best $\left(i . e ., p_{t}^{*}=c / \beta^{T-t}\right)$ provided that we can impose lump-sum taxes. It is true that the electric tariff is not a lump sum. However, as long as the electricity demand is quite inelastic we are very close to get it.

Suppose now that prices are constrained to be below a threshold $0<\bar{p}<$ $\infty$. Natural interpretations of $\bar{p}$ are that it is a (regulated) maximum price, either officially, or as perceived by the market players (i.e., firms believe that the regulation authorities will introduce price regulation if the price raises above $\bar{p}$ ). Let me assume now that $T$ tends to infinity. Then, from the analysis of equation (24) above, I have that the optimal reference price, $p_{t}^{*}$, would also tend to infinity. But this is not a plausible situation. In that case the following property holds:

Proposition 2 Let me assume that prices are constrained to be below a threshold $0<\bar{p}<\infty$. Then we have that $\exists \bar{T}$ such that $\forall T>\bar{T}$ it is not possible to implement the optimal reference price (i.e., $p_{t}^{*}=\frac{c}{\beta^{T-t}}$ ).

The intuition behind this proposition is the following. The optimal reference price depends positively on the length of the SCR period, $T$. The larger the value of $T$ the lower the impact of SCR payments on player's payoffs. Thus, only values 
of $p_{t}^{*}$ large enough would generate sufficient incentives to the firms in the market to exploit the stranded payments. Since there exists a (regulated) maximum price in the market, $\bar{p}$, it happens that for values of $T$ extremely large the regulator is not able to settle the optimal reference price because it would be larger than $\bar{p}$.

I am not considering the case in which $\gamma_{t}<0$. A negative value for $\gamma_{t}$ implies that $\beta^{T-t} p_{t}^{*}<c$, that is, the regulator is setting the adjusted reference price below the current marginal cost. Since this reference price is expected to reflect the forecasted competitive price in the liberalized market it is really hard to find a convincing argument which could explain the reason that could lead the regulator to settle this reference price below the current marginal cost.

In what follows I extend the model for treating the case of an oligopoly market with $n$ firms.

\subsection{The Oligopoly case}

So far, I have considered the performance of a duopoly market. The results there obtained generalize straightforwardly to the case of $n$ firms. In this section I analyze a similar game in which now I have $n$ firms in the markets and all of them have the opportunity to be compensated with SCR payments. That is

$$
1<\theta_{i}<0, \text { for all } i=1, \ldots, n \text {. }
$$

It is easy to prove that f.o.c.'s are now given by:

$$
\begin{array}{r}
\lambda-2 q_{i t}-\sum_{j \neq i} q_{j t}+\left[\beta^{T-t} p^{*}-\left[A-2\left(q_{i t}+\sum_{j \neq i} q_{j t}\right)\right]\right] \theta_{i}=0, \\
i=1, \ldots, n ; t=1, \ldots, T
\end{array}
$$


and thus reaction functions are denoted by:

$$
\begin{aligned}
q_{i t}^{e q}=\frac{1}{2}\left\{\lambda-\left[\left(1-\xi_{i}\right) \sum_{j \neq i} q_{j t}-\xi_{i} \gamma_{t}\right]\right\} & \\
i & =1, \ldots, n ; t=1, \ldots, T,
\end{aligned}
$$

It can be easily shown that equilibrium solutions are then given by

$$
q_{i t}^{e q}=\theta_{i} \lambda+\left[\frac{(n+1) \theta_{i}-1}{n-1}\right] \gamma_{t} i=1, \ldots, n ; t=1, \ldots, T .
$$

Aggregate equilibrium quantity at period $t$ is

$$
Q_{t}^{e q}=\sum_{i=1}^{n} q_{i t}^{e q}=\lambda+\frac{1}{n-1} \gamma_{t}, t=1, \ldots, T .
$$

so that the equilibrium price is:

$$
p_{t}^{e q}=c-\frac{1}{n-1} \gamma_{t}, t=1, \ldots, T .
$$

From previous equations it follows that all the conclusions summarized in Proposition (1) for the duopoly case apply also for the oligopoly case. Furthermore, from proposition (29), I can observe, like in a standard Cournot model without stranded costs, that when the number of firms becomes very large $(n \rightarrow \infty)$, the market price tend to be the competitive price, $c$. More formally,

Proposition 3 At each period the Nash equilibrium of the oligopoly model have the following properties:

a. The aggregate equilibrium quantity is not contingent on the distribution of SCR shares.

b. Hence, the equilibrium price in the market is also independent on the allocation of SCR payments among firms.

c. The existence of SCR payments necessarily encourage overall competition in the market forcing unambiguously to lower prices. 
d. The higher-SCR share firms supply at the market larger quantities than the lower-SCR share firms. Thus, the firm's market share is proportional to its $S C R$ allocations.

e. If $\gamma_{t}>0$, I can find in equilibrium market prices below marginal cost.

f. Setting always the reference price at marginal cost is suboptimal. Whenever $\gamma_{t}=0$, marginal cost pricing is the equilibrium strategy for this Cournot game with SCR payments. So that, it can be inferred that the optimal reference price does not depend on $n$, the number of firms in the market.

g. The equilibrium of the game with a large number of firms is approximately competitive.

The same intuitions that were explained in the duopoly case apply here when I compare the results obtained for the oligopoly case. Furthermore, I find that, like in a standard Cournot game (without SCR payments), the equilibrium game with a large number of firms is approximately competitive. This has a simple interpretation. Even with the introduction of SCR payments, each firm has only a small influence not only on the current market price but now also on the weightedaverage price and thus acts almost like a price taker.

Note that, like in the analysis of the duopoly game, I have that

$$
p_{t}^{e q}=c \Leftrightarrow \gamma_{t}=0, t=1, \ldots, T
$$

In other words,

$$
p_{t}^{e q}=c \Leftrightarrow p_{t}^{*}=\frac{c}{\beta^{T-t}}, t=1, \ldots, T .
$$

So that, the optimal reference price for the oligopoly game is identical to that one obtained in a duopoly market. I have as an optimal reference price a dynamic reference price. Also note that the optimal reference price is independent of the number of firms in the market. 


\subsection{Welfare Analysis}

In what follows I proceed to analyze welfare implications for the general oligopoly model presented in the previous section. As a benchmark case I have assumed that, in principle, regulator is capable to recover the reference SCR payment, $S^{*}$, from a lump-sum tax charged overall consumers in the market. In that case, it can be easily noted from equation (3) that whenever the weighted-average price, $\widehat{p}($.$) , is equal to the reference price, p^{*}$, selected by the regulator, then I have that the industry is going to be exactly paid the forecasted amount of money settled by the government at the beginning of the SCR period, $S^{*}$, that is, $S(\widehat{p}())=$. $S^{*}$. Assuming that all consumers in the market are homogeneous and there are no income effects in demand generated by the lump-sum taxes I then have that in the case that $\widehat{p}()=.p^{*}$, stranded costs have been recovered by the government via an efficient system. At the end of this section I briefly discuss a general scenario in which I relax this assumption.

I recognize this is an strong assumption but I use this setting as a benchmark case (the most positive case) in order to analyze the potential distortions that the SCR mechanism here presented can create in the market even when an ideal starting point has been settled by the government, the recovery of stranded costs using lump-sum fees. Note that even in that case in which $\widehat{p}()=.p^{*}$, and thus the total amount of stranded costs payments to be paid by the whole industry has been recovered in an efficient way, as long as the SCR mechanism would have influenced the incentives of the firms in the market inducing them to supply the market in such a way that ex post $\widehat{p}()=.p^{*}$, potential distortions may have been created. In fact I am able to show that, at least for the case in which firms present symmetric marginal cost, the key element of policy making is a proper settlement 
of the reference price, $p^{*}{ }^{16}$ Total welfare is not contingent on the allocation of SCR shares. I am able to derive the explicit set of conditions on the shape of the SC recovery mechanism such that the market allocation is efficient. The regulator's objective in this model is to maximize total welfare, that is, as the sum of consumer and producer surpluses. Note that in this market the regulator have the possibility of determine four parameters in the model: the allocation of SCR shares among firms, $\theta_{i}, i=1, \ldots, n$, the length of the SCR period, $T$, the determination of the reference price, $p^{*}$, and the reference $S C R$ payment, $S^{*}$. As I show below under certain conditions the regulator can induce the firms to the competitive price, so that the maximum welfare solution can be achieved.

\subsubsection{Net Consumer Surplus}

The net consumer surplus, when equilibrium output is denoted by $Q_{t}^{e q}$, is equal to

$$
C S=\sum_{t=1}^{T} \beta^{t-1} \int_{0}^{Q_{t}^{e q}}\left[p_{t}\left(Q_{t}\right)-p_{t}^{e q}\right] d Q_{t}-\beta^{T-1} \sum_{i=1}^{n} S_{i}\left(\widehat{p}_{i}^{e q}(.)\right)
$$

Since I have assumed that $p_{t}\left(Q_{t}\right)=A-\sum_{i=1}^{n} q_{i t}$, i.e., a standard linear demand then I have that previous equation can be written as

$$
C S=\sum_{t=1}^{T} \beta^{t-1} \frac{1}{2}\left(Q_{t}^{e q}\right)^{2}-\beta^{T-1} \sum_{i=1}^{n}\left\{\left[S_{i}^{*}-\sum_{t=1}^{T} \sum_{i=1}^{n}\left(\beta^{t-T}\left(A-Q_{t}^{e q}\right)-p^{*}\right) q_{i t}^{e q}\right] \theta_{i}\right\}
$$

Rearranging the terms and simplifying I have that

$$
C S=\sum_{t=1}^{T} \beta^{t-1}\left[A-\frac{1}{2} Q_{t}^{e q}-\beta^{T-t} p^{*}\right] Q_{t}^{e q}-\beta^{T-1} S^{*}
$$

\footnotetext{
${ }^{16}$ See section 4 below in which we demonstrate that the allocation of SCR payments among firms is also a key element in terms of welfare analysis in a model in which we allow asymmetric marginal cost between players in the game.
} 
From the previous equation I can conclude that consumer surplus is a decreasing function of the total output in the market. In other words I have that contrary to the predictions of a standard Cournot model, in a market with stranded-cost recovery payments consumers can be better off, all else being equal, with higher market prices. The intuition behind this fact is simple. An extra unit of output in the market generates now two opposite effects. On the one hand the standard effect generated in an otherwise identical market without stranded costs payoffs. The extra unit increases consumer surplus because, first, now consumers have to pay a lower price for the inframarginal units. But also, the reduction in the price generates that some consumers are now able to get the product. This both effect are comprises in the first term in equation (34). On the other hand I have now the effect of this extra unit in terms of SCR payments. Since SCR payments are a decreasing function of the price in the market, then I have now that a lower price forces consumers to pay a larger amount of money in terms of stranded costs compensation to the industry. And thus an extra unit of output, since it generates a decrease in the market price, has a negative influence on consumer surplus. When this second effect is stronger than the first one I can observe that consumer surplus is a decreasing function of the price market.

Replacing equation (28) into previous equation then I have that net consumer surplus in equilibrium is given by

$$
C S=\frac{1}{2(n-1)^{2}} \sum_{t=1}^{T} \beta^{t-1}\left[\lambda(n-1)+\gamma_{t}\right]\left[\lambda(n-1)-(2 n-1) \gamma_{t}\right]-\beta^{T-1} S^{*} .
$$

Proposition 4 In a Cournot game with stranded-cost recovery payments the net consumer surplus presents the following characteristics 
a. Net consumer surplus is independent of the allocation of SCR shares among firms in the market.

b. Net consumer surplus is a decreasing function of the prices in the market.

This is an important result for regulators. From the consumer's point of view, the allocation of SCR compensations among firms does not alter its level of overall level of welfare. It is natural, indeed I have already proved that the equilibrium outputs are not contingent on the assignment of SCR shares. A modification of these SCR shares redistribute payments among firms but it does not alter overall consumer surplus. The second result indicates that the introduction of SCR payments as a decreasing function of the market price can radically alter the incentives for all the agents in the market. Such is the case here, in which I show that consumers are not better off with lower prices any more, since its objective now is trying to avoid the payments of SCR compensations. So that, consumers are better off, all else equal, with lower amounts of output in the market.

\subsubsection{Producer Surplus}

In a market with SCR payments the industry can obtain profits from two different ways. On the one hand, standard production payoffs which are denoted by the first term in the equation below. But also, form SCR compensations. The second term in equation (37) reflects this last option.

$$
P S=\sum_{t=1}^{T} \beta^{t-1}\left[p_{t}^{e q}-c\right] Q_{t}^{e q}+\beta^{T-1} \sum_{i=1}^{n} S_{i}\left(\widehat{p}_{i}(.)\right),
$$


Replacing equation (6) into the equation above and rearranging the terms it is easy to demonstrate that producer surplus can also be written as

$$
P S=\sum_{t=1}^{T} \beta^{t-1} \gamma_{t} Q_{t}^{e q}+\beta^{T-1} S^{*}
$$

A simple analysis of equation (38) allows me to conclude that as long as the reference price, $p^{*}$, is sufficiently larger that the marginal cost, $c$, the industry as a whole achieves larger levels of welfare whenever the level of output in the market increases. That is, the total producer surplus is an increasing (decreasing) function of the output (price) in the market. The intuition behind this fact is as follows. As long as the reference price is high enough industry as a whole would be strongly tempted to exploit the possibility of obtaining SCR payments. Since SCR compensations are a decreasing function of the market price, under certain conditions, the industry oversupply the market in order to drive prices down, and thus, increasing its profits via SCR payments. Note also that the industry as a whole is indifferent to the allocation of the SCR shares among firms. This does not mean that individually each firm's behavior is not contingent on the distribution of SCR payments. But since this allocation reflects only a redistribution of the same "cake" among the firms, in the aggregate the allocation of SCR shares does not matter for producer surplus analysis. Furthermore, I can infer from the previous equation that when the regulator settles the reference price, in such a manner that

$$
p^{*}=\frac{c}{\beta^{T-t}},
$$

(i.e, $\left.\gamma_{t}=0\right)$, then I have that producer surplus remains always constant. The industry is unconcerned to the total output in the market. The aggregate profits for the whole industry remains in any case invariable. 
Replacing equation (28) into equation (38) I get

$$
P S=\sum_{t=1}^{T} \beta^{t-1}\left[\gamma_{t}\left(\lambda+\frac{1}{n-1} \gamma_{t}\right)\right]+\beta^{T-1} S^{*},
$$

More formally, proposition (5) characterizes all the results discussed below.

Proposition 5 In a Cournot game with stranded-cost recovery payments and symmetric marginal costs total producer surplus presents the following characteristics.

a. Producer surplus is independent of the allocation of SCR shares among firms in the market.

b. If $\gamma_{t}>0$, then I have that producer surplus is a decreasing (increasing) function of the aggregate output (market prices) supplied at the market.

c. If $\gamma_{t}=0$, producer surplus remains always constant, independently to the equilibrium output.

\subsubsection{Total welfare}

Once I have analyze consumer and producer surpluses I proceed now to study welfare implications of the existence of SCR payments which can be inferred from the model presented in previous sections. The regulator's objective is maximize total welfare. ${ }^{17}$ Several authors and regulatory bodies have pointed out that stranded-cost recovery represents a zero-sum game, and thus its existence represents a simple transfer of wealth between incumbent utilities (or utility investors)

\footnotetext{
${ }^{17}$ The regulator's objective is maximize total welfare. Where total welfare is define as the simple sum of consumer and producer surpluses. Hence, in principle, we do not care about redistributive concerns which could make regulators to overweight consumer surplus.
} 
and consumers. ${ }^{18}$ I am able to show that only partially this statement is correct. There is no doubt about the transference of wealth between incumbent firms in the market and consumers that SCR payments mechanisms impose. However, it is not always true that stranded-cost recovery represents a zero-sum game. This fact will depend on the explicit mechanism designed to make effective the magnitude and the allocation of the stranded-cost payments. In this section I am able to show that even in the case in which SCR payoffs could be recovered from the consumers via non-distortionary mechanisms, (for instance via lump-sum taxes), the existence of SCR payments can alter total welfare in the game. The intuition is as follows, given that the stranded costs component is calculated ex post and contingent on the market prices, its existence may interfere with rational behavior in the production market, modifying the incentives of the firms in the market, so that, the equilibrium outputs. As I show below, these can be no bad news at all because under certain conditions the regulator could convert this problem into a benefit inducing the market to an efficient allocation.

Let $W$ denote total welfare, where

$$
W=C S+P S
$$

Replacing equation (33) and equation (37) into the previous one I get

$$
W=\sum_{t=1}^{T} \beta^{t-1}\left(A-\frac{1}{2} Q_{i t}^{e q}-c\right) Q_{i t}^{e q} .
$$

Note that this expression of total welfare is identical to that one that I find in the analysis of a standard Cournot model. This seems reasonable since as I

\footnotetext{
${ }^{18}$ Brenan and Boyd (1997), at p. 42 , recognizes that "stranded costs recovery is widely regarded as a zero-sum game". See also http://www.state.va.us/scc/news/streprt4.htm/ where the Virginia State Corporate Commission adds "[I]n a nutshell, stranded costs and margins may be described as potential wealth transfers between utility investors and utility consumers which result from changing the rules of the game".
} 
have already said the total amount of money to be paid via SCR payments from the consumers to the industry represents simple transfers of wealth between the economics agents in the market.

Lemma 1 SCR payments may alter firms' incentives strategies in the production market, and thus, the allocation of SCR payments in a market not always represent a zero sum-game.

From the analysis of equation (41) it can be inferred that only in those cases in which firms' incentives are not altered by the settlement of SCR payoffs I could ascertain that SCR payments represent a zero-sum game. But I have already demonstrated in subsection 3.1 and subsection 3.2 that equilibrium outputs in a market with stranded costs are not equivalent to that ones that I would have obtained in an otherwise similar market without stranded costs. And thus, it is shown SCR payments not always represents a zero sum-game and a simple transfer of wealth between economic agents in the market.

Replacing equilibrium solution, given by equation (29), into equation (41) I get

$$
W=\sum_{t=1}^{T} \frac{1}{2} \beta^{t-1}\left[(A-c)^{2}-\left(\frac{\gamma_{t}}{n-1}\right)^{2}\right] .
$$

Let $W_{p c}$ denote total level of welfare under perfect competition. I can observe two facts from a simple analysis of previous equation.

$$
\begin{gathered}
\lim _{n \rightarrow \infty} W=\sum_{t=1}^{T-1} \frac{1}{2} \beta^{t-1}(A-c)^{2}=W_{p c}, \text { and } \\
\text { If } \gamma_{t}=0, \text { for all } t=1, \ldots, T, \text { then I have that } W=W_{p c}
\end{gathered}
$$

The next proposition contains the conclusions that can be derived from the analysis of equation (42) above: 
Proposition 6 In a Cournot game with stranded-cost recovery payments and symmetric marginal costs total welfare presents the following characteristics:

a. Total welfare is independent on the allocation of SCR shares among firms in the market.

b. Total levels of welfare are not altered by actual SCR entitlements but by the mechanism designed to its determination.

c. The equilibrium of the game with a large number of firms is approximately competitive.

d. If $\gamma_{t}=0$, then I have that

d.1. Producer surplus remains always constant, and thus, only consumer surplus matters for welfare analysis.

d.2. The number of firms in the market does not alter the total level of welfare in any case.

d.3. The standard maximum welfare solution of a typical Cournot game with perfect competition is achieved. The optimal SC recovery mechanism is independent of the number of firms.

Powerful insights for regulatory policymaking can be derived from previous proposition. First, I can derive from result $a$. that, the allocation of SCR shares are not a key element in the context of symmetric firms. It can be a key element in terms of redistributive implications among firms in the market but it is not in terms of efficiency concerns. ${ }^{19}$ Result $b$. in proposition (6) is reflecting

\footnotetext{
${ }^{19}$ We show in section 4.1 that SCR shares can also be a key elements in terms of efficiency considerations when we allow for asymmetric marginal costs among firms in the market.
} 
the following fact. Actual amount of SCR payments to be paid to the industry are not reflected in total welfare equation since it represents a simple transfer of welfare among players in the game. Hence, at least directly, a larger or lower level of SCR payments does not modify the total level of welfare. It is the pricecontingent mechanism, developed to calculate the proper amount of stranded payments, the key element that modifying firms' incentives induce changes in the level of total welfare. In other words, the actual amount of SCR payments would not alter total level of welfares if a different mechanism had been determined which was not contingent to the equilibrium outputs in the market. Result $c$. has a simple interpretation. With the introduction of a large number of firms in the market, each player has only a small influence not only on the current market price but now also on the weighted-average price and thus acts almost like a price taker. It an be easily shown that an increase in the number of firms in the market increases consumer surpluses, (i.e., $\left.\frac{\partial C S}{\partial n}>0\right)$, reduces producer surpluses, $\left(\right.$ i.e., $\left.\frac{\partial P S}{\partial n}<0\right)$, and has a positive effect in terms of total welfare, (i.e., $\left.\frac{\partial W}{\partial n}>0\right)$. Result $d$. is an important outcome for regulators, since it is identifying an important regulatory tool, a dynamic reference price, $p_{t}^{*}$, in order to achieve the competitive solution. Result $d$. allows the regulator to settle optimally the reference price in such a manner that market forces induce players to the maximum welfare solution. Whether the regulator is able to the regulator is able to settle an optimal reference price for each period, $p_{t}^{*}$, which is a timeadjustment of the marginal cost, (i.e., $\left.p_{t}^{*}=\frac{c}{\beta^{T-t}}\right)$, then I know, from section 3.1 and section 3.2, that marginal cost is induced to be the equilibrium price for all the periods in the game. And thus, maximum welfare solution is achieved. Setting the reference price at marginal cost is suboptimal. Note also that the 
optimal reference price, (i.e., $\left.p_{t}^{*}=\frac{c}{\beta^{T-t}}\right)$, is independent of the number of firms in the market.

\section{Extensions of the model}

In what follows I am dealing with two extensions of the model presented in previous sections. First up, I consider a model in which firms in the market have asymmetric marginal costs. For simplicity I analyze a duopoly market but similar conclusions here obtained can be easily extended to the case of oligopoly markets. Subsequently I deal with entry deterrence concerns in a Cournot game with stranded costs.

\subsection{Asymmetric marginal costs}

In this subsection, I assume that $c_{i}<c_{j}$, so that, firm $i$ enjoys lower production costs than its rival, firm $j$. As I show below, in a market with SCR payments and asymmetric marginal costs SCR shares may be an important regulatory tool. In fact, I am enabled to show that an unappropriated allocation of SCR shares may deliver productive inefficiency in the market and that, from the regulator's point of view, it is optimal to assign higher SCR shares to those firms with lower marginal costs (and thus, ex-ante higher market shares).

Reaction functions are denoted by:

$$
q_{i t}=R_{i t}\left(q_{j t}\right)=\frac{1}{2}\left\{\left(A-c_{i}\right)-\left[\left(1-\xi_{i}\right) q_{j t}-\xi_{i}\left(\beta^{T-t} p^{*}-c_{i}\right)\right]\right\}, t=1, \ldots, T .
$$

The Cournot equilibrium then becomes:

$$
q_{i t}^{e q}=\theta_{i}\left(A-c_{i}\right)+\left(3 \theta_{i}-1\right)\left(\beta^{T-t} p^{*}-c_{i}\right)+\left(c_{j}-c_{i}\right)\left(1-2 \theta_{i}\right), t=1, \ldots, T
$$


From previous equation I have that $\partial q_{i t}^{e q} / \partial c_{i}=-2 \theta_{i}<0$, and hence I get that the firm's output decreases with its marginal cots. An increase in a firm's marginal cost shifts the firm's reaction curve down. More interestingly, when SCR payments are symmetrically shared among generators, [i.e., $\theta_{i}=\theta_{j}=\frac{1}{2}$, and thus, $\left.\xi_{i}=\xi_{j}=1\right]$, then I have that equilibrium outputs are not dependent on rivals' marginal costs. So that, a firm does not react to a change in rivals' marginal costs, $\left[i, e, . d q_{i t}^{e q} / d c_{j}=R_{i t}^{\prime}\left(q_{j t}\right) \frac{\partial q_{i t}}{\partial c_{j t}}=0\right]$. This has a simple intuition. From equation (43) I get that when SCR payments are equally shared among firms then a firm does not react to changes in rivals' output $\left[i . e ., R_{i t}^{\prime}\left(q_{j t}\right)=0\right]$. A reduction in rival's marginal cost generates an increase in rivals' output, but since the increment in rival's output decreases firm $i$ 's production profits in the same amount that it increases SCR payoffs, then I have that hat, it does not alter firm i’s equilibrium output.

Let's analyze the case in which SCR payments are asymmetrically allocated. Without loss of generality I am assuming that $\theta_{i}>\theta_{j}$. It can be easily shown that now I have that firm i's output increases with its competitor's marginal costs, $\left(d q_{i t}^{e q} / d c_{j}=1-2 \theta_{i}<0\right)$. However, firm $j$ 's output decreases with firm $i$ 's marginal $\operatorname{cost}\left(d q_{j t}^{e q} / d c_{i}=1-2 \theta_{j}<0\right)$. The intuition is as follows, an SCR share, $\theta_{i}$, larger than $\frac{1}{2}$ implies, as I have already demonstrated in subsection 3.1, that for firm $i, q_{j t}$ is a strategic complement of $q_{i t}$, [i.e., $\left.R_{i t}^{\prime}\left(q_{j t}\right)>0\right]$. Hence, a reduction in rival's marginal cost, which induces firm $j$ to increase its level of output, is followed by an increment on firm $i$ 's level of output. The opposite occurs to firm $j$. An SCR share lower than $\frac{1}{2}$, implies that for firm $j, q_{i t}$ is a strategic substitute of $q_{j t}$, [i.e., $\left.R_{j t}^{\prime}\left(q_{j t}\right)<0\right]$. And thus, firm $j$ reacts to a reduction in firm $i$ 's marginal cost, which results in an increment of firm $i$ 's output, with a lower level of output. 
It can be easily generalize to $n$ firms the equilibrium output, given by equation (44), for the case of a duopoly market. The equilibrium output for an oligopoly case would be given by

$$
\begin{aligned}
q_{i t}^{e q}= & \theta_{i}\left(A-c_{i}\right)+\left[\frac{(n+1) \theta_{i}-1}{n-1}\right]\left(\beta^{T-t} p^{*}-c_{i}\right)+ \\
& +\left[\frac{1}{n-1} \sum_{j \neq i} c_{j}-c_{i}\right]\left(1-2 \theta_{i}\right), t=1, \ldots, T .
\end{aligned}
$$

The aggregate equilibrium outcome at each period $t$ is then given by

$$
Q_{t}^{e q}=A+\frac{1}{n-1}\left(\beta^{T-t} p^{*}-\sum_{i=1}^{n} c_{i}\right), t=1, \ldots, T .
$$

Proposition 7 In a Cournot game with stranded costs and asymmetric marginal cots I find that :

a. A firm's output decreases with its marginal costs.

b. When SCR are equally shared among firms in the market, $\left[i . e ., \theta_{i}=\theta_{j}=\frac{1}{2}\right]$, each firm supplies its optimal output independently on rival's outcome.

c. When SCR are asymmetrically allocated among firms in the market, [i.e., $\left.\theta_{i} \neq \theta_{j}\right]$, then I get that

c.1. The lower-SCR share firm increases its output when raises competitor's marginal cost, and

c.2. The higher-SCR share firm reacts to an increment of rival's marginal costs with a reduction on its level of output.

d. The aggregate equilibrium quantity is not contingent on the distribution of SCR shares. 


\subsubsection{Welfare Analysis}

I proceed very briefly to analyze policy making implications which can be derived form allowing in the benchmark model the existence of asymmetric marginal costs. As I show below, with the introduction of this asymmetry in the market I am enable to identify the allocation of SCR shares as a powerful regulatory tool. In subsection 3.3 I demonstrated that the allocation of SCR shares is not a key elements in terms of policy making implications since, under the assumption of symmetric marginal costs, I proved that total welfare is totally independent to the distribution of SCR payments among firms in the market. However, it comes up that a proper allocation of these SCR shares must be a prominent labor for the regulatory agency in those cases in which firms present asymmetric marginal costs. I am enabled to show that an unappropriated allocation of SCR shares may deliver productive inefficiency.

To be a bit more specific, let me consider total welfare function for the exact Cournot game with stranded costs with asymmetric marginal costs. It can be proved that it is given by:

$$
W=\sum_{t=1}^{T} \beta^{t-1}\left[\frac{1}{2}\left(\sum_{i=1}^{n} q_{i t}^{e q}\right)^{2}+\sum_{i=1}^{n}\left(A-\sum_{i=1}^{n} q_{i t}^{e q}-c_{i}\right) q_{i t}^{e q}\right],
$$

Replacing the equilibrium outcome, given by equation (45), into the previous equation and rearranging the terms I have that total welfare can also be expressed , in terms of SCR-weighted-average marginal costs, $\sum_{i=1}^{n} \theta_{i} c_{i}$, as:

$$
\begin{gathered}
W=\sum_{t=1}^{T} \beta^{t-1}\left\{\Theta+\Gamma-\Phi \sum_{i=1}^{n} \theta_{i} c_{i}\right\}, \text { where } \\
\Theta \equiv \frac{1}{2}\left\{A^{2}-\left[\frac{1}{n-1}\left(\beta^{T-t} p^{*}-\sum_{i=1}^{n} c_{i}\right)\right]^{2}\right\}
\end{gathered}
$$




$$
\begin{gathered}
\Gamma \equiv \frac{1}{n-1}\left(\beta^{T-t} p^{*}-\sum_{i=1}^{n} c_{i}\right) \sum_{i=1}^{n} c_{i}+\sum_{i=1}^{n} c_{i}^{2}, \text { and } \\
\Phi \equiv A+\frac{1}{n-1}\left[(n+1) \beta^{T-t} p^{*}-2 \sum_{i=1}^{n} c_{i}\right] .
\end{gathered}
$$

And important result for regulators can be derived from a simple analysis of equation (48):

Proposition 8 If $\Phi>0$, then I have that it is optimal from the regulator's point of view to assign higher SCR shares to those firms with lower marginal cots (and thus ex-ante higher market shares).

This a simple interpretation. ${ }^{20}$ I have already shown that equilibrium outputs are not affected by the allocation of SCR shares among firms. Furthermore I know that those firms with larger SCR shares supply at the market larger amount of outputs than those ones with lower SCR shares in order to exploit their SCR payments. And thus, if this is the case, a regulator would be interested in assign higher SCR shares to those firms more efficient, to those firms with lower marginal costs, and lower SCR shares ton those other firms with larger marginal costs. SCR shares arises as a key element of policy making when I am considering a market in which firms enjoy asymmetric marginal costs.

I can derive a powerful insight for regulatory policymaking from previous proposition. Since a larger allocation of SCR shares induces firms to increase the output in the market then I may conclude that an unappropriated allocation of SCR shares may deliver productive inefficiency. Let me imagine a duopoly market in which I have $\theta_{j}>\theta_{i}$ and $c_{i}<c_{j}$, and thus, higher SCR payments are

\footnotetext{
${ }^{20}$ Note that the assumption that $\Phi$ is positive is a plausible assumption when we are considering markets large enough, so that, levels of the parameter $A$ sufficiently large.
} 
assigned to that firm with larger marginal costs. In that case it is easy to obtain from equation (45) that

$$
q_{j t}^{e q}>q_{i t}^{e q} \text { iff }\left[A+3 \beta^{T-t} p^{*}-2\left(c_{i}+c_{j}\right)\right]>\frac{c_{j}-c_{i}}{\theta_{j}-\theta_{i}}, t=1, \ldots, T .
$$

and thus I have that the probability of productive inefficiency in a market with asymmetric marginal costs is higher the lower the magnitude of marginal costsasymmetry among firms, $c_{j}-c_{i}$, all else equal. Furthermore, the probability of productive inefficiency increases with an increment of the SCR share allocated to the most expensive firm.

\subsection{Entry deterrence}

In previous sections I have considered a setting in which all firms in the market are paid SCR payments. However, in a dynamic market in which new entrants participate in the market only incumbent firms are allowed for recovering SCR compensations. In this subsection I am dealing with this situation. I am able to show that in a market with SCR payments incumbents firms may deter the entry to more efficient firms. And thus, I can conclude that the existence of SCR payments may have anticompetitive effects because they could allow incumbent firms to delay or prevent desired new competition.

I am considering the case in which I also have $n$ firms in the market but now only $n_{1}$ are incumbent firms (type 1-firms), and thus, they are obtaining SCR payments. Furhtermore, I have $n_{2}$ new entrant firms (type 2-firms) which do not obtain SCR payments, such that $n=n_{1}+n_{2}$. Let's contemplate the case in which all of $n_{1}$ firms present an identical constant marginal cost, $c_{1}$, and new entrant firms are more efficient and can produce the same good at an identical constant marginal cost, $c_{2}$, such that $c_{2}<c_{1}$. Let $q_{i t}$ denote the quantity that firm $i$ of 
type 1 supplies to the market at period $t$, and $x_{j t}$ represent the quantity that firm $j$ of type 2 supplies to the market at period $t, i=1, \ldots, n_{1}, j=1, \ldots, n_{2}, t=$ $1, \ldots, T$. By simplicity I denote

$$
Q_{t} \equiv \sum_{i=1}^{n_{1}} q_{i t}, \text { and } X_{t} \equiv \sum_{j=1}^{n_{2}} x_{j t}
$$

The demand for the product sold by the firms is $p_{t}\left(Q_{t}, X_{t}\right)$ and for simplicity, it is assumed that $p_{t}()=.A-\left(Q_{t}+X_{t}\right)$, i.e., a standard linear demand.

For any firm $i$ of type $1 \mathrm{I}$ have that its intertemporal profit in any period $t$, $\Pi_{i t}^{1}\left(q_{i t}, q_{-i t}, X_{t}\right) \equiv \Pi_{i t}^{1}$, is given by,

$$
\Pi_{i t}^{1}=\sum_{k=t}^{T} \beta^{k-t} \Pi_{i k}+\beta^{T-t} S_{i}(\widehat{p}(.)), i=1, \ldots, n_{1} ; t=1, \ldots, T,
$$

where $S_{i}(\widehat{p}()$.$) is now given by$

$$
S_{i}\left(\widehat{p}_{i}(.)\right)=S_{i}^{*}-\left\{\left(\widehat{p}(.)-p^{*}\right)\left[\sum_{k=1}^{T}\left(\sum_{j=1}^{n_{1}} q_{j k}+\sum_{l=1}^{n_{2}} x_{l k}\right)\right]\right\} \theta_{i}, i=1, \ldots, n_{1},
$$

and $\widehat{p}_{i}($.$) is denoted by$

$$
\widehat{p}(.)=\frac{\sum_{k=1}^{T} \beta^{k-T} p_{k}\left(\sum_{j=1}^{n_{1}} q_{j k}+\sum_{l=1}^{n_{2}} x_{l k}\right)}{\sum_{k=1}^{T}\left(\sum_{j=1}^{n_{1}} q_{j k}+\sum_{l=1}^{n_{2}} x_{l k}\right)},
$$

For any firm $l$ of type 2 I have that its intertemporal profit in any period $t$, $\Pi_{l t}^{2}\left(x_{l t}, x_{-l t}, Q_{t}\right) \equiv \Pi_{l t}^{2}$, is given by,

$$
\Pi_{l t}^{2}=\sum_{k=t}^{T} \beta^{k-t}\left(p_{k}-c_{2}\right) x_{l k}, l=1, \ldots, n_{2} ; t=1, \ldots, T,
$$

It can be shown that solutions to this game are now given by:

$$
\begin{aligned}
q_{i t}^{e q}= & \theta_{i}\left(A-c_{1}\right)+\frac{1}{n_{1}+n_{2}-1}\left\{\left[\left(n_{1}+1\right) \theta_{i}-1\right]\left(\beta^{T-t} p^{*}-c_{1}\right)\right. \\
& \left.+n_{2}\left[\theta_{i}\left(\beta^{T-t} p^{*}-c_{1}\right)-\left(c_{1}-c_{2}\right)\left(1-2 \theta_{i}\right)\right]\right\},
\end{aligned}
$$




$$
\begin{array}{r}
i=1, \ldots, n_{1} ; t=1, \ldots, T \text {, and } \\
x_{j t}^{e q}=\frac{1}{n_{1}+n_{2}-1}\left[n_{1}\left(c_{1}-c_{2}\right)-\left(\beta^{T-t} p^{*}-c_{2}\right)\right], \\
j=1, \ldots, n_{2} ; t=1, \ldots, T .
\end{array}
$$

Aggregate equilibrium output and price equilibrium at each period $t$ are then given by:

$$
\begin{gathered}
Q_{t}+X_{t}=A+\frac{1}{n-1}\left[\beta^{T-t} p^{*}-c_{1} n_{1}-n_{2} c_{2}\right], t=1, \ldots, T, \text { and } \\
p_{t}^{e q}(.)=c_{2}-\frac{1}{n-1}\left[\beta^{T-t} p^{*}-c_{2}-n_{1}\left(c_{1}-c_{2}\right)\right], t=1, \ldots, T .
\end{gathered}
$$

From equation (61) I can observe that it could be the case that equilibrium prices, $p_{t}^{e q}($.$) , may be below new entrants' marginal costs, c_{2}$. This would deter new entry since these new entrant firms are not allowed to obtain SCR payments, so that, in the case of entry they would enjoy negative profits. This problem comes up significant specially when the reference price, $p^{*}$, is large enough because it induces incumbent firms to achieve lower equilibrium prices in order to exploit SCR payments. By contrast, it can be noted that this problem becomes less prominent when the difference in marginal costs among incumbents and entrants is sufficiently important. In this situation the equilibrium price is never low enough to deter entry.

\section{Concluding Remarks}

In this paper I have developed a dynamic model of Cournot competition which take explicitly into account a particular mechanism designed for settling stranded 
costs payments. I have shown that, under certain regulatory conditions, efficient competition can be achieved in a market with stranded-cost recovery payments. Whether this goal is succeeded or not depends on the exact rules used to define these entitlements mechanism design is the key element in welfare analysis outcomes. Even though the paper reveals that an optimal stranded-cost recovery policy can act as a countervailing force to market power and high prices, it also demonstrates that, an unappropriated allocation of the SCR payments among firms in the market may promote productive inefficiency to arise in the market. Furthermore, I have also demonstrated that under certain conditions SCR payments could allow incumbent firms to delay or prevent desired new competition. The main purpose of the paper has been to address the welfare implications of the settlement of stranded costs payments in a formal dynamic model. 


\section{References}

[1] Brennan, T. J., and J. Boyd (1997), 'Stranded Costs, Takings, and the law and Economics of Implicit Contracts', Journal of Regulatory Economics, Vol. 77, pp. 71-92.

[2] Energy Information Administration Report, 'The Changing Structure of the Electric Power Industry: An Update', DOE/EIA-0562(96) (Washington DC, December 1996), http://www.eia.doe.gov/cneaf/electricity/chg_str/.

[3] García-Martín, J. A. (1999), 'Spot Market Competition with Stranded Costs in the Spanish Electricity Industry', Mimeo, CEMFI.

[4] Hovenkamp, H. (1999), 'The Takings Clause and Improvement Regulatory Bargains', Yale Law Journal, Vol. 108, pp. 801-834.

[5] Joskow, P. and R. Schmalensee (1986), 'Incentive Regulation for Electric Utilities', Yale Journal on Regulation.

[6] Joskow, P. L. (1996), 'Does Stranded Cost Recovery Distort Competition?', The Electricity Journal, April, pp. 31-45.

[7] Joskow, P. (2000), 'Deregulation and Regulatory Reform in the U.S. Electric Power Sector', Mimeo, MIT.

[8] Kahn, E. (1994), 'Can Regulation and Competition Coexist? Solutions to the Stranded Cost Problem and Other Conundra', The Electricity Journal, October, pp. 23-35.

[9] Kühn, K.-U, and B. Jullien (1998), 'Price Caps and Price Floors: Entry Liberalization and the Stranded Asset Issue', Mimeo, CEMFI. 
[10] Kühn, K.-U. and P. Regibeau (1998), ¿Ha Llegado la Competencia?: Un Análisis Económico de la Reforma de la Regulación del Sector Eléctrico en España', Informes del Institut d'Anàlisi Econòmico, CSIC.

[11] Lasheras, M. A. (1998), 'Stranded Costs in the Spanish Electricity Industry', Working Paper 006/98, CNSE.

[12] National Economic Research Associates, 'Rewriting the Rules of the Road: Retail Wheeling and Competition in Electric Generation', (New York, NY, March 1994).

[13] Rose-Ackerman, S. and J. Rossi (2000), 'Disentangling Deregulatory Takings', Working Paper No. 7, FSU College of Public Law.

[14] Sidak, J. G. and D. F. Spulber (1997), Deregulatory Takings and the Regulatory Contract, Cambridge UK: Cambridge University Press.

[15] Tirole, J. (1988) The Theory of Industrial Organization, Cambridge: MIT Press. 


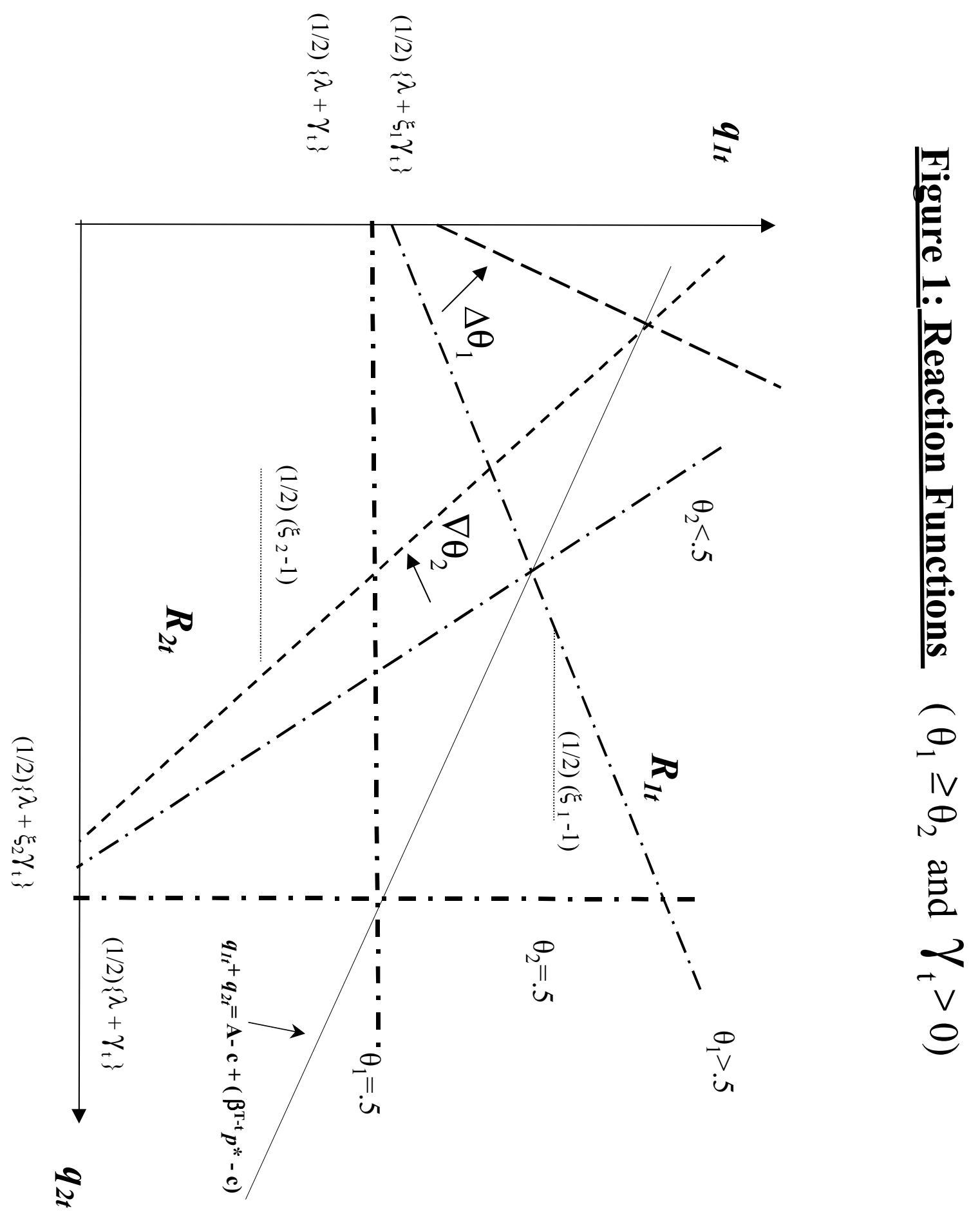

